\title{
Two Design of New Toll Station Based on Probability \\ Distributions and Queuing Theory
}

\author{
Le Wang \\ North China Electric Power University, Baoding 071000, China \\ 644591488@qq.com
}

Abstract: On the basis of Probability Distributions and Queuing Theory ${ }^{[1-4]}$, two kinds of new toll stations are designed, which are the "shunting" toll station and "series parallel compound" toll station. And this article calculates the average queue length, the average waiting time of vehicles, the throughput and costs of the new toll stations and make comparisons with traditional toll stations. The results show that the two new toll stations all make improvements to the shape, size and merge mode and both play a very good role in improving.

Keywords: Queuing Theory; “shunting” and “series parallel compound” toll station

\section{Introduction}

Using the probability distribution model to analyze the performance of the traditional toll station with three lanes and eight tollbooths, we find that the traditional toll station has the following drawbacks:

1. The driver's independent choice has a central tendency, which put a lot of pressure to the central toll gate. This causes a long average queuing time in central toll lane, a difficulty in changing lanes and other adverse effects.

2. There is a big difference in the pressure among the eight toll gates, which causes an inadequate use of resources.

3. The flexibility and safety of the vehicle are adversely affected by the optional lane change on the toll plaza.

\section{The "shunting" Toll Station}

\subsection{Introduction and Analysis of the Structure}

Taking the drawbacks above into account, we creatively give a design of "shunting" toll station in order to alleviate the queuing pressure and reduce the construction cost.

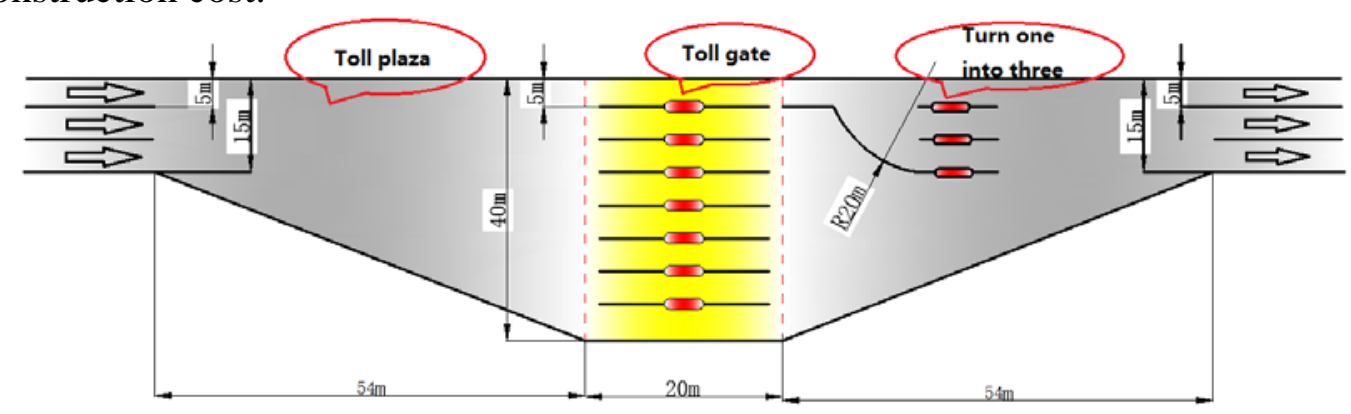

Fig.1: The "shunting” Toll Station

The improvements are as follows: 
- "Turn one into three". Implement a diversion scheme for the most pressure toll gate. Aim to shorten the queue length of toll roads, increase the freedom of vehicles and promote the vehicle lane changing.

- The new design scheme gives reasonable provisions to lane change: First, vehicle on the first driving road can only go to toll gate one and two. Second, vehicle on the second driving road can only go to toll gate three, four and five. Third, vehicle on the third driving road can only go to toll gate six v seven and eight.

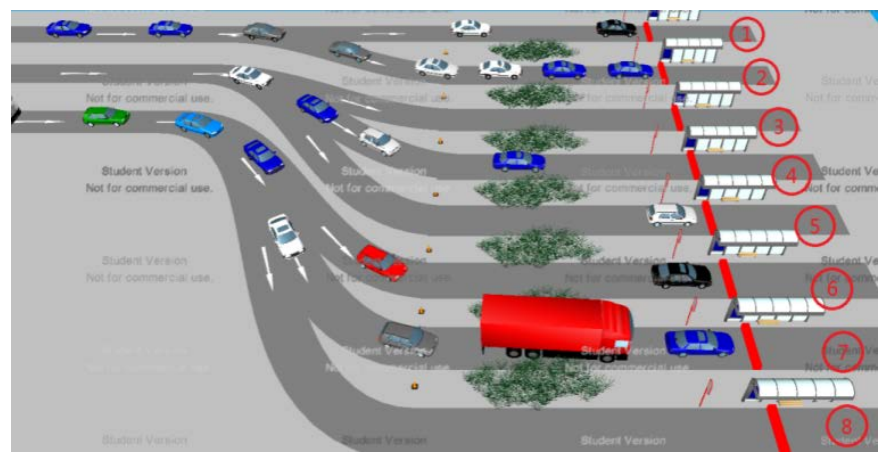

Fig.2: The former toll plaza

Taking the data of toll station as an example, we calculate the various indicators of the new toll station.

\subsection{Quantifying Service Level Indicators}

We get the average number of vehicles in different toll gate and the average waiting time in different toll gate.

Table 1: The indicators

\begin{tabular}{ccccccccccc}
\hline Gate number & 1 & 2 & 3 & 4 & 5 & 6 & 7 & 8 & 9 & 10 \\
\hline $\begin{array}{c}\text { Average number } \\
\text { of vehicles[unit] }\end{array}$ & 0.32 & 0.32 & 0.32 & 1.67 & 0.87 & 0.87 & 0.87 & 0.81 & 0.81 & 0.81 \\
\hline $\begin{array}{c}\text { Average waiting } \\
\text { time[s] }\end{array}$ & 2.56 & 2.56 & 2.56 & 13.36 & 6.92 & 6.92 & 6.92 & 6.47 & 6.47 & 6.47 \\
\hline
\end{tabular}

\subsection{Comparisons with Traditional Toll Stations}

Compared with traditional toll station, the "shunting" toll station distributes the service load reasonably, and the service level is increased. The differences are shown by the histogram below.

If we regulate the lane changing in the toll plaza, the service load in each toll gate is basically balanced. Compared with traditional toll station, it makes better use of resources and relieves stress for queuing. 


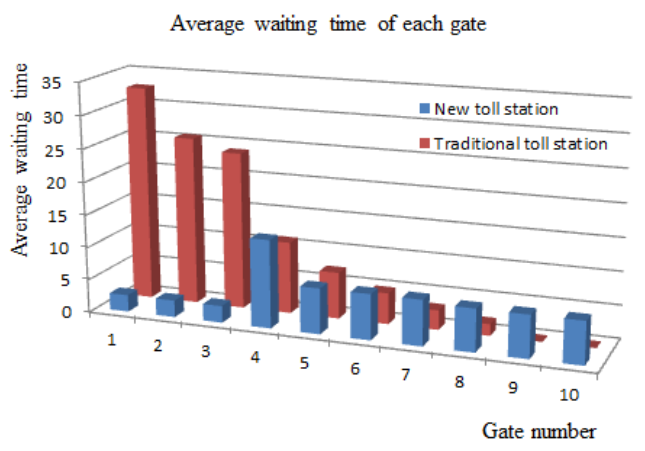

Fig.3: Average waiting time of each gate

The waiting time of each toll gate in the "shunting" toll station is relatively short and it is difficult to congest. In terms of costs, the length of the former toll plaza in "shunting" toll station is only $54 \mathrm{~m}$, only $1 / 3$ of that of the traditional toll station.

\section{3. "Serial and Parallel Compound" Toll Station}

\subsection{Introduction and Analysis of the Structure}

In addition to the model mentioned above, in order to reduce the area of toll plaza and the construction cost effectively, we combine the serial collection and the parallel collection and put forward the "serial and parallel compound" toll station. We plan the shape, size, and merge mode reasonably and the sketch is as follows:

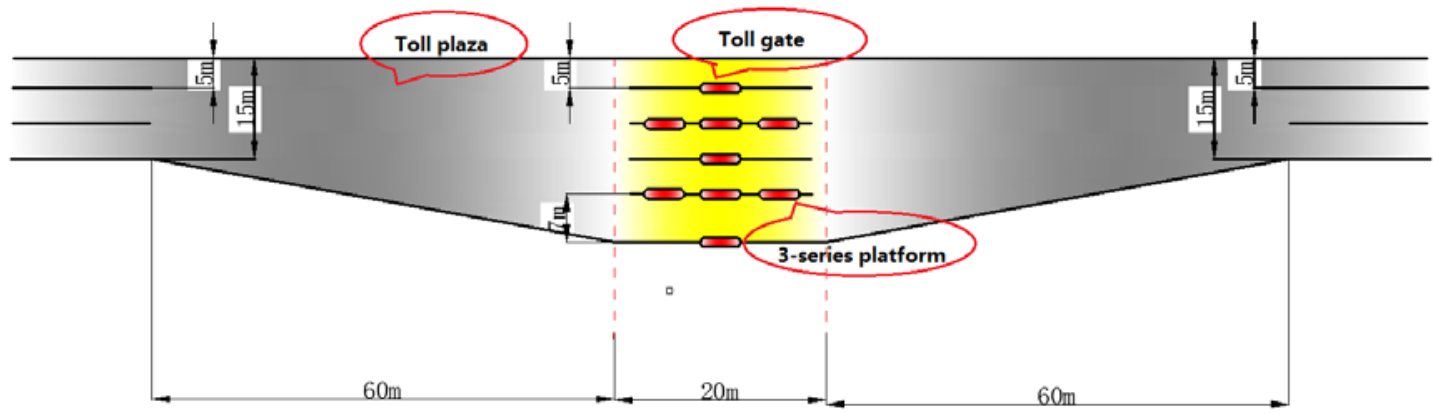

Fig.4: The "Serial and Parallel Compound" Toll Station

The improvements are as follows:

- Add warning bars at the entrance of toll plaza to classify different types of vehicles. Lane 1 and lane 2 are the lanes for cars, while lane 3 is designed for big trucks.

- Change the arrangement of the tollbooths. The original 8-platform parallel mode is changed into the mode of two 3 -series platforms and 3 single parallel platforms.

\subsection{Quantifying Service Level Indicators}

Table 2: The indicators

\begin{tabular}{cccccc}
\hline Gate number & 1 & 2 & 3 & 4 & 5 \\
\hline $\begin{array}{c}\text { Average number } \\
\text { of vehicles[unit] }\end{array}$ & 0.89 & 1.10 & 0.89 & 1.09 & 1.09 \\
\hline $\begin{array}{c}\text { Average waiting } \\
\text { Time(s) }\end{array}$ & 7.13 & 3.25 & 7.13 & 3.24 & 10.9 \\
\hline
\end{tabular}




\subsection{Comparisons with Traditional Toll Stations}

Compared with traditional toll station, the "serial and parallel compound" toll station plans the merge mode and the collection platforms rationally. The differences from the traditional toll station are shown by the histogram below:

As there are lanes special for carts, the overall capacity of toll station and the service level are both increased.

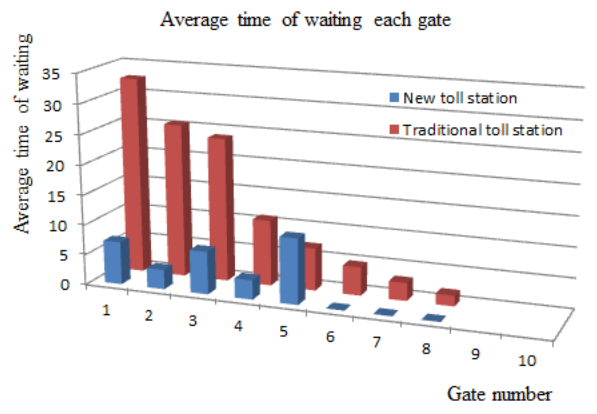

Fig.5: The average time of waiting each gate

The figure above shows the average waiting time in each gate. The waiting time of each toll gate in the new toll station is short and it is difficult to congest. In the design scheme, the new toll station has the advantages of less length and width. The construction area of the toll station reduces by nearly $64.5 \%$.

\section{Conclusions}

The two new toll stations all make improvements to the shape, size and merge mode and both play a very good role in improving.

In the "shunting" toll station, the traffic flow is equally divided to each toll gate, which makes full use of service in each toll gate and keeps the queuing distance of each toll gate within a small range. It reduces the length of the toll plaza and save the construction costs.

In the "serial and parallel compound" toll station, we divide the vehicles in different types. By arranging the collection platforms, it saves the width of the toll plaza as well as the construction costs.

\section{References}

[1] Chunlei Wu, Yulin Chang, Configuration Research of Toll-gate on Freeway [J] . Highway Engineering, 2008 (5):172-175

[2] Jun Xie. Study of Analysis and Evaluation for Expressway Capacity and Service Quality [D] . Xi'an: Chang'an University. 2007

[3] Min Zhang, Hong Chen, Xiaowu Wu, Safety Evaluation Model for Expressway Toll Stations [J] . China Safety Science Journal, 2009 (10):139-144

[4] Yimei Luo, Yi Song, Baoquan Ji. Study on Improvement of Passthrough Capacity of Mainline Toll-stations on Expressways [J] . Logistics Technology, 2013(5):285-330 